University of Louisville

ThinkIR: The University of Louisville's Institutional Repository

\title{
Characterization of plethodontid TIMP-like protein (PTP) and its role in tissue remodeling during pheromone gland development.
}

Andrew Knight

Follow this and additional works at: https://ir.library.louisville.edu/honors

Part of the Chemistry Commons

\section{Recommended Citation}

Knight, Andrew, "Characterization of plethodontid TIMP-like protein (PTP) and its role in tissue remodeling during pheromone gland development." (2016). College of Arts \& Sciences Senior Honors Theses. Paper 106.

http://doi.org/10.18297/honors/106

This Senior Honors Thesis is brought to you for free and open access by the College of Arts \& Sciences at ThinkIR: The University of Louisville's Institutional Repository. It has been accepted for inclusion in College of Arts \& Sciences Senior Honors Theses by an authorized administrator of ThinkIR: The University of Louisville's Institutional Repository. This title appears here courtesy of the author, who has retained all other copyrights. For more information, please contact thinkir@louisville.edu. 
Characterization of Plethodontid

TIMP-like Protein (PTP) and its Role in Tissue

Remodeling During Pheromone Gland Development

\author{
By \\ Andrew Knight \\ Submitted in partial fulfillment of the requirements for \\ Graduation summa cum laude \\ and \\ for Graduation with Honors from the Department of Chemistry \\ University of Louisville
}

May, 2016 


\section{$\underline{\text { Table of Contents }}$}

I. Abstract 2

II. Introduction 3

III. Specific Aims $\quad 11$

$\begin{array}{ll}\text { IV. Materials and Methods } & 14\end{array}$

$\begin{array}{lll}\text { V. Results and Discussion } & 21\end{array}$

$\begin{array}{ll}\text { VI. Conclusions } & 25\end{array}$

$\begin{array}{ll}\text { VII. References } & 29\end{array}$ 


\begin{abstract}
$\underline{\text { Abstract }}$
Plethodon shermani is a species of lungless salamander that has a complex courtship ritual during which the female straddles the male's tail. The male then uses a submandibular mental gland to secrete nonvolatile proteinaceous pheromones to increase females' receptivity to mating. Investigation of the pheromone extract indicated the presence of a protein, termed Plethodontid TIMP-like protein (PTP), with no pheromonelike activity that bears sequence similarity to a group of proteins known as Tissue Inhibitors of Matrix Metalloproteinases (TIMPs). PTP was functionally characterized by measuring its ability to inhibit a range of mouse and human Matrix Metalloproteinases (MMPs). The results of this experiment indicated that PTP is capable of inhibiting at least one human MMP, hMMP-1, a collagenase. Confocal fluorescence microscopy of mental gland cross sections probing for PTP, collagen, and Plethodontid Receptivity Factor (PRF) revealed that PTP is colocalized with pheromones in the mental gland, which helps to explain why PTP is found in the pheromone extract. It is hypothesized that regular PTP secretion during mating acts as a biochemical signal that the mating season is ongoing and that the mental gland should be maintained. Additionally, a recombinant PTP was also expressed in P. pastoris for use in further structural characterization.
\end{abstract}




\section{Introduction}

The tissue remodeling process is important to the development of all animals and plays a role in cancer metastasis. Seasonally expressed tissues provide a model to study the tissue remodeling process in a consistent and reproducible way. The red-legged salamander, Plethodon shermani, is a terrestrial, lungless salamander indigenous to the mountains of western North Carolina (Figure 1) that seasonally expresses a submandibular mental gland that produces nonvolatile proteinaceous pheromones used to increase female receptivity to mating. $P$. shermani has been used in previous studies as a model for studying reproductive behavior and pheromone signaling. ${ }^{[1]}$ The courtship ritual and the pheromones of $P$. shermani have been studied extensively due to their unique nature. ${ }^{[1-5]}$ During courtship, females will straddle a male's tail in a process known as tail straddling walk. The male will apply pheromones directly to the female's nares using a submandibular mental gland Figure 2. Delivery of the pheromone causes the female to be more receptive to mating with the male due to the effect of two major pheromones: Plethodontid Receptivity Factor (PRF) and Plethodontid Modulating Factor (PMF). ${ }^{[6]}$ However, a third protein, Plethodontid TIMP-like Protein (PTP), comprises approximately $10 \%$ of the extract and does not seem to have pheromonal activity as determined by measuring neuronal activation within the vomeronasal organ (VNO) in females (Figure 3). ${ }^{[7]}$

Using NCBI BLAST, the amino acid sequence of PTP that had been determined earlier was found to be similar to that of Tissue Inhibitors of Metalloproteinases (TIMPs) with an E value of $4 \mathrm{x} \mathrm{e}^{-16}$ (hTIMP-1) using NCBI's protein database. Matrix Metalloproteinases (MMPs) catalyze the degradation of structural proteins in the 
extracellular matrix such as collagen. ${ }^{[8]}$ TIMP/MMP binding is responsible for a wide variety of functions including cell proliferation, differentiation, and tissue remodeling. ${ }^{[9]}$ The expression of TIMPs tightly regulate the location and action of constitutively expressed MMPs in their various roles. ${ }^{[10]}$ TIMPs are capable of inhibiting a large range of metalloproteinases and are therefore considered broad-spectrum inhibitors. TIMPs are ubiquitous in animals: vertebrates generally maintain four TIMP gene copies compared to a single TIMP in invertebrates. In humans, all four TIMPs inhibit the 23 human Matrix MetalloProteinases (hMMPs) to some level with the exception of hTIMP-1, which has low affinity for the membrane-type hMMPs: hMMP-14, hMMP-16, and hMMP-24 as well as for hMMP-19. ${ }^{[10,11]}$ Additionally, the TIMPs are also able to inhibit other nonMMP metalloproteinases such as A Disintegrin And Metalloproteinases (ADAMs), A Disintegrin And Metalloproteinases with ThromboSpondin Motifs (ADAMTSs) and other matrix metalloproteinases. ${ }^{[12]}$ ADAMs and ADAMTS have been implicated in control of membrane fusion, cytokine and growth factor shedding, and cell migration. ${ }^{[13]}$ Out of the four vertebrate TIMPs, PTP was found to be most similar to TIMP-1 by comparing the primary sequence of PTP to that of the four vertebrate TIMPs (Figure 4). However, comparison of the sequences from vertebrate TIMPs, invertebrate TIMPs, and PTP revealed that PTP is more distantly related to vertebrate TIMPs than vertebrate TIMPs are to one another (Figure 5). Because of its similarity to the TIMPs, PTP was hypothesized to have TIMP-like activity and possibly facilitate mental gland development. After primary sequence comparison and functional characterization as an MMP inhibitor, it was determined that PTP has TIMP-like activity and based on the data, it likely results from an ancient gene duplication that predates the other TIMP divergence. 
The location of PTP expression within the mental gland was unknown. It was therefore difficult to hypothesize the exact mechanism for PTP action in mental gland tissue remodeling processes. Understanding where PTP is located within the gland and its relative expression over time gives a more complete picture of mental gland development.

As part of the characterization, future studies will investigate the solution structure of PTP using ${ }^{15}$ N NMR experiments. Since isotopically labeled PTP is necessary for those experiments, a recombinant PTP must be produced. The 12 cysteine residues involved in disulfide bond formation in PTP complicate recombinant protein expression. Typical E. coli protein expression strains have reducing cytoplasm that is not conducive to disulfide bond formation and lack an endoplasmic reticulum, which has been shown to be the site of disulfide bond formation in eukaryotes. ${ }^{[14]}$ Numerous bacterial strains have been developed to address this problem. For example, New England Biolab's SHuffle T7 E. coli, which has been modified to express disulfide bond isomerase DsbC and has an oxidizing cytoplasm to allow for disulfide bond formation.

Several attempts using the NEB SHuffle T7 strain were executed under a variety of temperature, media, and IPTG concentrations. Small quantities of rPTP were expressed as a fusion protein with Maltose Binding Protein, which has been shown to have chaperone-like activity. ${ }^{[15]}$ However, the amount of protein produced was insufficient for further experimentation. In order to express correctly folded rPTP in sufficient quantities, Pichia pastoris was utilized as an alternative protein expression vector. 
$P$. pastoris is a species of methylotrophic yeast that was identified as a viable protein expression vector in $1990 .{ }^{[16]}$ The chemical environment is critical in correct protein folding and disulfide bond formation. Both $P$. pastoris and $P$. shermani are eukaryotic. In eukaryotes, disulfide bond formation takes place primarily in the endoplasmic reticulum. Therefore, expression in P. pastoris is more similar to the native protein expression in $P$. shermani than expression in a prokaryotic vector, like E. coli, would be. $P$. pastoris has also shown improvements in protein processing, protein folding, and posttranslational modification over E. coli and Saccharomyces cerevisiae. ${ }^{[17]}$ $P$. pastoris is also able to secrete recombinant products into the extracellular environment when a signaling sequence is expressed on the recombinant protein. The signaling peptide is not bound to the final product as it is cleaved during secretion. 


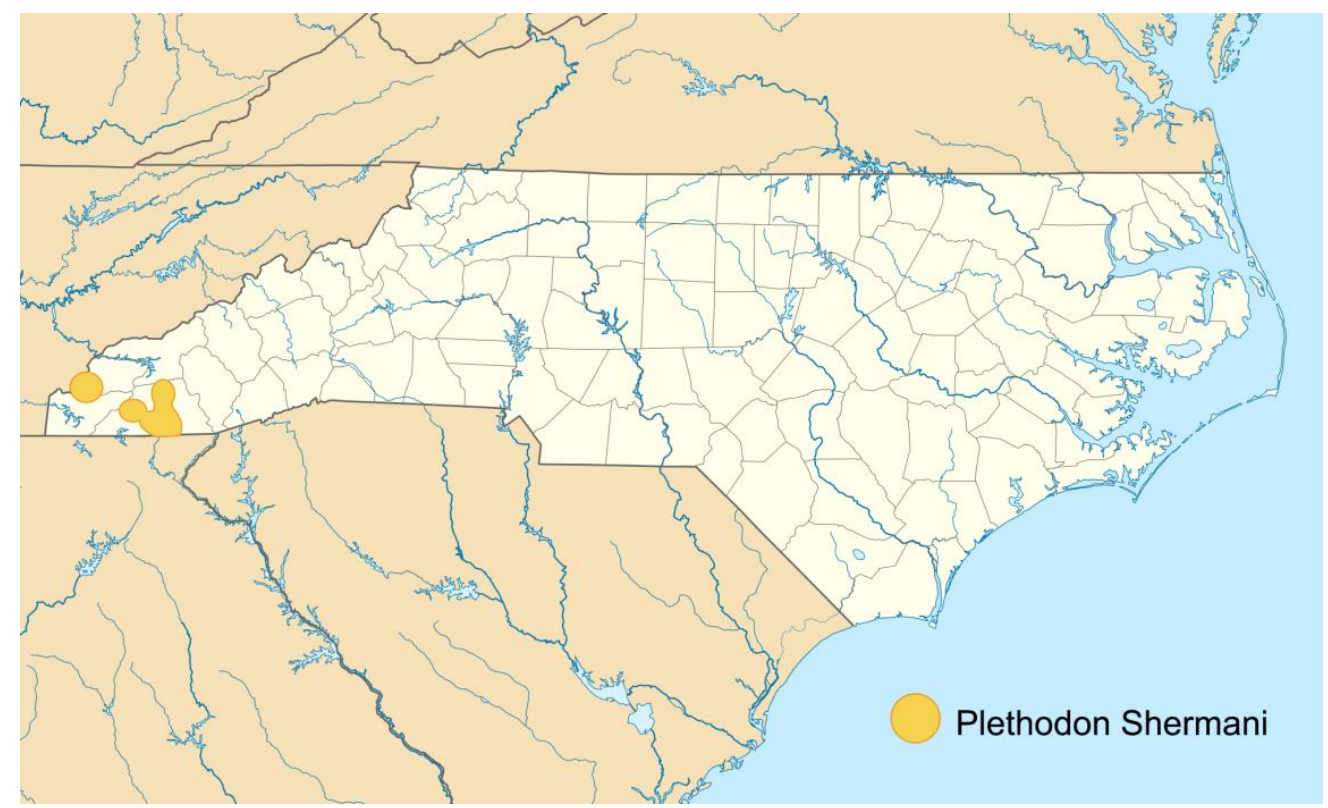

Figure 1. Distribution map of Plethodon shermani.

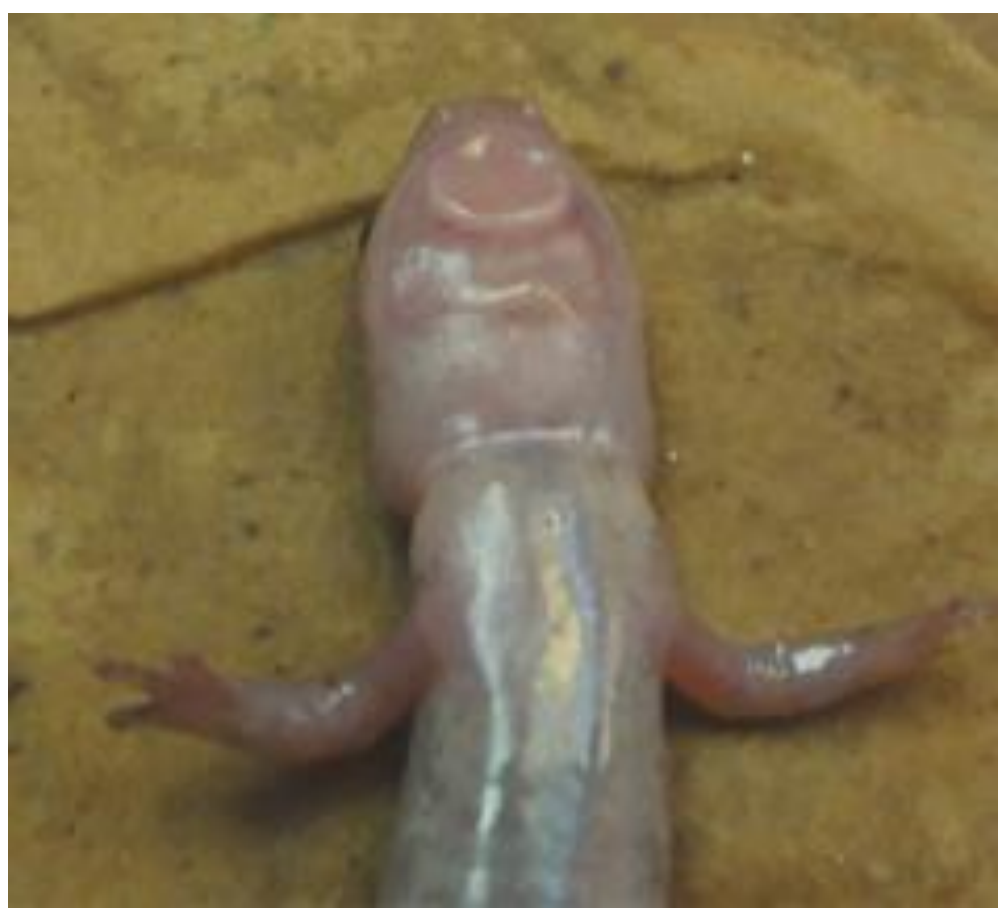

Figure 2. Prominent submandibular mental gland of a male $P$. shermani during the mating season. 


\section{PBS \\ Control}

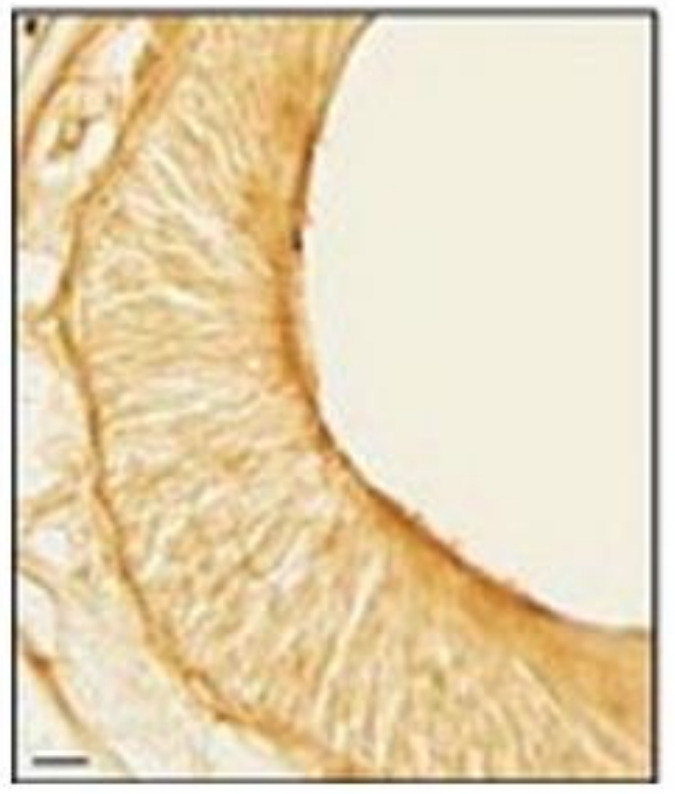

\section{Male Mental Gland Extract}

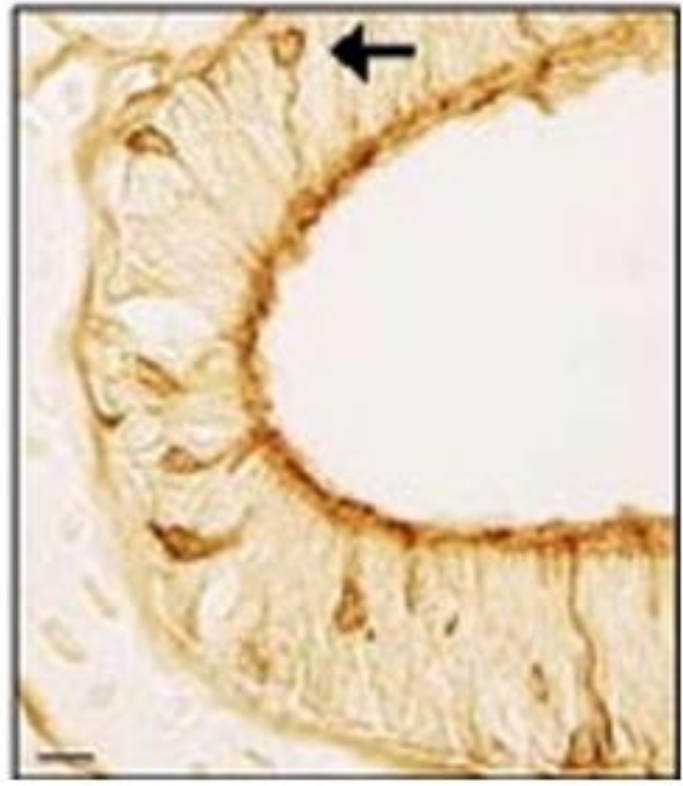

Figure 3. VNO tissue sections treated with a mixture of agmatine and either PBS, as a control, or the male mental gland extract. Upon neuronal activation, agmatine is taken up into the neurons within the VNO. The tissue is then thoroughly rinsed, fixed, and stained for agmatine using an anti-agmatine antibody. The black arrow indicates an activated neuron that is agmatine-immunoreactive. The number of activated neurons can be counted and used as a quantification of the reactivity of the VNO neurons with a substrate. The scale bars are $10 \mu \mathrm{m} .{ }^{[18]}$ 


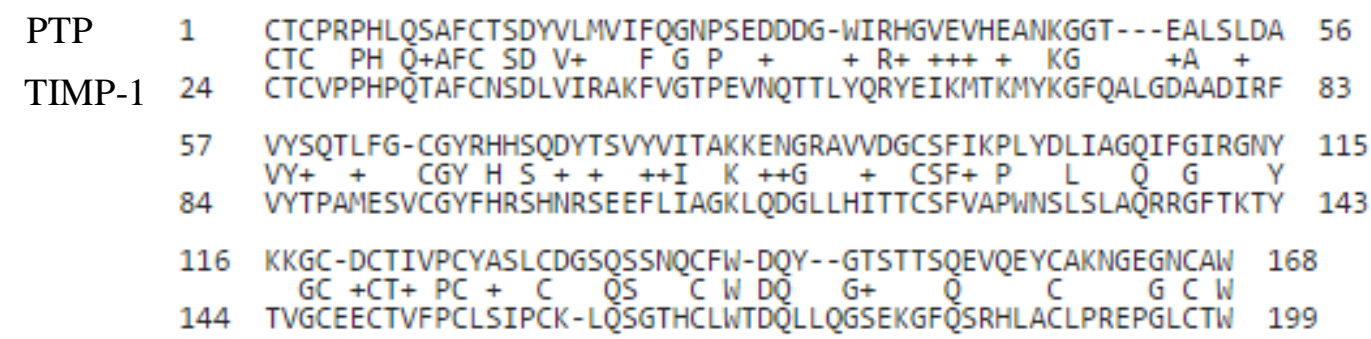

Figure 4. Primary amino acid sequences of TIMP-1 starting at amino acid 24 and PTP starting at its $\mathrm{N}$-terminus. The amino acids written between the two lines represent exact matches between the two sequences while the plus signs represent synonymous substitutions. The proteins share $48 \%$ positive residue matches that are either synonymous or identical indicating a structural similarity between TIMP-1 and PTP. The E score is $4 \mathrm{e}-16$.

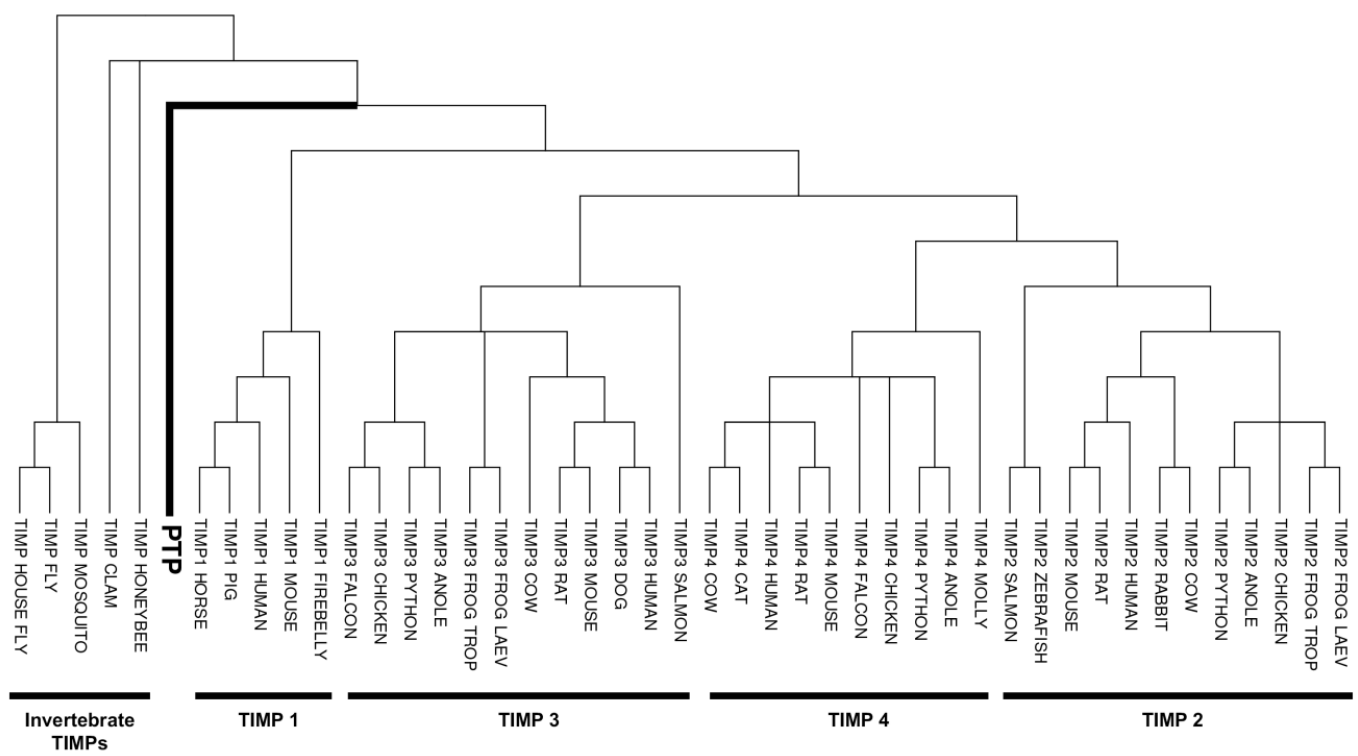

Figure 5. Gene tree comparing PTP to both invertebrate and vertebrate TIMP orthologs.

These data suggest that PTP may represent an ancient gene duplication that predates most vertebrate lineages. 


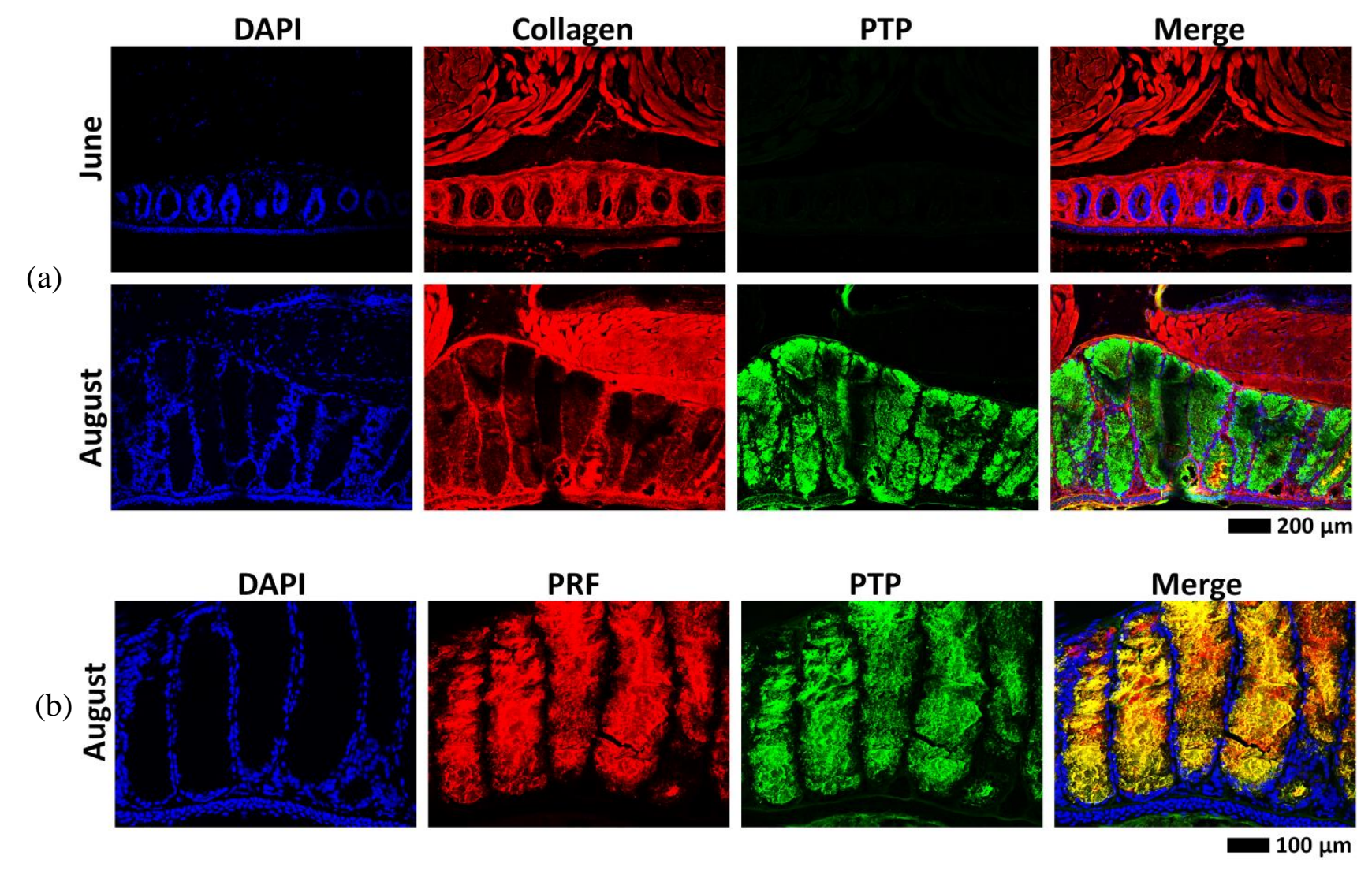

Figure 6. Fluorescence Confocal Microscopy

(a) PTP expression and localization for mental glands at different stages of development (6/13 and 8/13) using $\alpha$-PTP (green), $\alpha$-collagen (red), and DAPI nuclear stain (blue)

(b) PRF and PTP expression and localization for mental glands by immunohistochemistry using $\alpha$-PTP/biotin (green), $\alpha-\mathrm{PRF} /$ Atto-633 (red) and DAPI nuclear stain (blue). 


\section{$\underline{\text { Specific Aims: }}$}

\section{$\underline{\text { Aim 1: Functional Characterization }}$}

As the mental gland has a tightly regulated seasonal development, it has been proposed that PTP could act as a TIMP and inhibit secreted MMPs, which would otherwise degrade the gland. Since PTP is secreted during courtship, it could serve as an indicator that the pheromone has been delivered. Once the courtship season ends, absence of PTP could indicate that the mental gland is no longer needed. Consequently, regular secretion of PTP during tail straddling walk may serve as a unique chemical signal that the courtship season is ongoing. It has been observed qualitatively that isolated males undergo recession of their mental glands. It is likely that expression of PTP is controlled by external signaling pathway such as testosterone levels or RNA-binding proteins as both have been shown to influence mental gland development. ${ }^{[19,20]}$

To better characterize the function of PTP, its activity as an MMP inhibitor was quantitatively assessed. This determination of PTP's ability as an MMP inhibitor was made by measuring the rate of cleavage of the fluorogenic substrate OMNIMMP ${ }^{\circledR}$ RED fluorogenic substrate by a variety of human and mouse MMPs with and without the presence of PTP. Upon cleavage, the substrate fluoresces; the amount of florescence can be used as a measure of the rate of cleavage. Therefore, information about the enzyme kinetics with and without the presence of PTP can be gathered. ${ }^{[21]}$ It is important to note that MMPs from P. shermani are not available for use in this assay, but the conserved nature among MMPs ${ }^{[22]}$ and the broad range of TIMP inhibition ${ }^{[23]}$ served as indicators that inhibition may be observed between a TIMP from $P$. shermani and human MMPs. 
Indeed, inhibition was observed when using PTP in conjunction with hMMP-1 indicating that PTP does possess TIMP-like activity.

\section{Aim II: Characterization of the Expression and Localization of PTP}

In order to observe the expression and localization of PTP at different stages of mental gland development, immunofluorescence confocal microscopy were employed to visualize PTP (Plethodon TIMP-like Protein), PRF (Plethodon Receptivity Factor) —a pheromone, and Collagen II-a substrate for MMP-1. ${ }^{[24]}$ Antibodies against PTP and collagen were used to detect each protein. DAPI was used to visualize the nuclei. The micrographs were overlaid to visualize co-localization during different points in gland development. The images revealed that PTP is localized with PRF in the mental gland. Collagen indicated the that the extracellular matrix was extensively remondeled during gland development.

\section{Aim III: Expression of rPTP}

A structural analysis of PTP will provide further insight into the function of PTP and can be utilized in future studies to examine its ability to bind to various substrates such as MMPs. NMR can provide valuable structural data. In order to obtain NMR data, an isotopically labeled recombinant protein needed to first be obtained. This was first attempted by cloning the PTP gene for overexpression in E. coli to allow expression of a recombinant PTP (rPTP). rPTP was expressed as a fusion protein with Maltose Binding Protein, which has previously been demonstrated to increase properly folded recombinant

TIMPs in an E. coli expression system. ${ }^{[25]}$ After numerous attempts to optimize the 
expression of rPTP in an E.coli system, it was concluded that the yield of correctly folded rPTP would be impractically low for pursuing NMR studies. In order to obtain larger quantities of correctly-folded rPTP, its gene was cloned for overexpression in P. pastoris. Utilizing this method was promising as $P$. pastoris, a species of yeast, is eukaryotic and thus possesses an endoplasmic reticulum, which has the oxidizing environment in its lumen that is often necessary for the correct folding of other disulfide bonded proteins that are naturally found in eukaryotic cells. This strategy led to the expression of many proteins that could not be expressed in E. coli ${ }^{[26]}$. The expression conditions were optimized and ${ }^{15} \mathrm{~N}$ labeled rPTP was expressed using ${ }^{15} \mathrm{~N}$ ammonium sulfate as the nitrogen source in the media.The resulting rPTP was concentrated, and purified via ultracentrifugation and size exclusion chromotography on a Sephadex G75 column.

Further purification was not required since the recombinant protein was secreted into the media which contains relatively few other proteins ${ }^{[27]}$. The structures of PTP and rPTP were compared via reverse phase chromatography and were found to have the same retention times. Reverse phase chromatography is highly sensitive. Even small changes in the conformation of the protein would change its hydrophobicity enough to result in a different retention time. Since the retention times were effectively the same in both cases, rPTP is believed to be structurally believed to have a similar structure to native PTP Further analysis will be conducted by determining the disulfide bonding pattern. It should also be noted that rPTP was designed to have identical primary structure as PTP without any additional amino acids or modifications that are not found in native PTP. 


\section{$\underline{\text { Materials and methods: }}$}

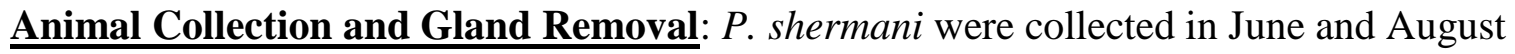
2013 from Wayah Bald in western North Carolina. The submandibular mental glands were removed from $P$. shermani during survival surgery under anesthesia. Pheromone was extracted from the gland by incubating with $0.8 \mathrm{mM}$ acetylcholine chloride in Amphibian Ringer's solution. The extract was then incubated for 1 hour followed by centrifugation at $10,000 \times \mathrm{g}$ for $10 \mathrm{~min}$, the supernatant was removed and re-centrifuged prior to storage at $-80^{\circ} \mathrm{C}$.

MMP Inhibition Assay: The MMP inhibition activity of PTP was measured using an MMP substrate, OmniMMP ${ }^{\mathrm{TM}}$ Red fluorogenic substrate peptide, which fluoresces when it is cleaved. The rate of cleavage is measured by the level of fluorescence. The assay was performed with a negative control (no PTP) a positive control (the chemical inhibitor NNGH) and 5 concentrations of PTP ranging from 20pM to 200nM. The lower concentrations were chosen based off of endogenous levels of TIMPs and wide range was used to account of a decreased association affinity between $P$. shermani PTP and human MMPs. MMP- 1,2,7,8,9, and 13 were tested. The assay was performed in 50mM HEPES, $10 \mathrm{mM} \mathrm{CaCl}_{2}, 0.05 \%$ Brij-35, at $\mathrm{pH}$ 7.5. The fluorescence of the reaction was measured every minute for 2 hours, and the rate was quantified by linear regression. The assay was repeated for MMP-1 using a broader gradient of 10 different PTP concentrations from $7.8 \mathrm{nM}$ to $4 \mu \mathrm{M}$. 
Fluorescent Confocal Microscopy: Mental glands from June and August 2013 were fixed using $4 \%$ paraformaldehyde and $8 \mu \mathrm{m}$ sections isolated by microtomy. Four slides from each time point were used such that the two antibody treatments were tested in duplicate. One set of slides was treated with DAPI, anti-Collagen, and anti-PTP. The other set was treated with DAPI, anti-PRF, and anti-PTP. The slides were photographed using a confocal microscope.

Synthesis and Refolding of rPTP: Expression of rPTP as a fusion protein with Maltose Binding Protein was performed using an E. coli expression system. The construct included a short linker (SGAAAAGGSDP) between the two proteins and a hexahistidine tag sequence on the N-terminus of the Maltose Binding Protein. The PTP coding regions were PCR amplified from mental gland cDNA and confirmed by Sanger sequencing. The amplified sequence was ligated into the pET45b-based vector using T4 DNA Ligase (New England Biolabs). The plasmid was then transformed into T7 Express lys Y/Iq chemically competent $E$. coli. Clones were initially cultured in $100 \mathrm{~mL}$ of LB media with ampicillin (LB/Amp) at $28^{\circ} \mathrm{C}$ overnight. The culture was then diluted up to an OD600 of 0.05 in $1 \mathrm{~L}$ of $\mathrm{LB} / \mathrm{Amp}$. This culture was grown to a final OD600 of $\sim 0.6$ at $28^{\circ} \mathrm{C}$ at which point IPTG was added to a final concentration of $0.1 \mathrm{mM}$.

After a 24 hour induction period the cultures were centrifuged at 2,000 x g for 30 minutes at $4^{\circ} \mathrm{C}$. The cultures were then resuspended into $2.2 \mathrm{~mL}$ of lysis buffer $(50 \mathrm{mM}$ $\mathrm{NaCl}, 50 \mathrm{mM}$ Tris $\mathrm{pH} 8.0,2 \mathrm{mM}$ EDTA, 0.1\% Triton X-100). The lysates were then thoroughly sonicated. $240 \mathrm{uL}$ of $10 \mathrm{mg} / \mathrm{mL}$ lysozyme solution was added to each lysate. Sonication was used to disrupt the cell membranes and fragment the bacterial DNA. 
Lysozyme was used to enzymatically break down the bacterial cell walls. The lysates were then incubated at $25^{\circ} \mathrm{C}$ for one hour. The lysates were then frozen at $-80^{\circ} \mathrm{C}$. The lysates were then thawed and centrifuged at $10,000 \mathrm{x}$ g for 10 minutes. The supernatant was then decanted from the pellet.

The protein was purified on a nickel-chelation column, but disulfide scrambling was observed so the protein was fully reduced and denatured in $4 \mathrm{M}$ urea, $0.1 \%$ Triton $\mathrm{X}$, $20 \mathrm{mM} \beta \mathrm{ME}, 150 \mathrm{mM} \mathrm{NaCl}$, and $50 \mathrm{mM}$ Tris $\mathrm{pH}$ 8.0. Refolding was attempted via rapid dilution and dialysis. The refolding attempts produced insufficient properly folded rPTP for further experimentation. Inclusion bodies were not found to include significant quantities of rPTP. Nickel column fractions were also tested for rPTP, but no significant rPTP was present.

\section{$\underline{\text { Strain selection }}$}

Expression optimization included screening two different $P$. pastoris strains: $\mathrm{X}-33$ and KM71H. The two strains differ by their methanol utilization rate. X-33 utilizes methanol at a faster rate than $\mathrm{KM} 71 \mathrm{H} . \mathrm{KM} 71 \mathrm{H}$ has been designated Mut ${ }^{\mathrm{S}}$ for $\underline{\text { Methanol utilization }}$ slow and $\mathrm{X}-33$ has been designated $\mathrm{Mut}^{+}$for fast methanol utilization. Expression levels of each strain were measured by lysing the culture after one day of induction in $1 \%$ methanol. The protein abundance was determined by measuring the absorbance at $280 \mathrm{~nm}$. The relative amounts of rPTP were also measured by SDS-PAGE and Coomassie staining. The KM71H strain was determined to give the highest rPTP yield and was used for all subsequent expressions. 


\section{Preparing competent $P$. pastoris}

X-33 and KM71H P. pastoris were streaked on YPD agar plates and incubated at $30^{\circ} \mathrm{C}$ for two days. A single colony was selected from the YPD plate and used to inoculate a $10 \mathrm{~mL}$ YPD culture. The culture was then grown at $30^{\circ} \mathrm{C}$ to an $\mathrm{OD} 600$ of 0.6 to 1.0 . The culture was then pelleted at $2,000 \mathrm{x}$ a a $4^{\circ} \mathrm{C}$ for 5 minutes. The pellet was resuspended in 10mL of Solution I (sorbitol, ethylene glycol, DMSO) provided with the

Invitrogen EasySelect ${ }^{\mathrm{TM}}$ P. pastoris and then pelleted again at $2,000 \mathrm{x} \mathrm{g}$ at $4^{\circ} \mathrm{C}$ for 5 minutes. The pellet was then resuspended into $1 \mathrm{~mL}$ of Solution I. $100 \mu \mathrm{l}$ of the suspension was aliquoted into sterile $0.6 \mathrm{~mL}$ tubes. The tubes were wrapped in paper towels and frozen at $-80^{\circ} \mathrm{C}$ until needed for transformation.

\section{Preparing rPTP for transformation in P. pastoris:}

The yeast shuttle vector $\mathrm{pPICZ} \alpha \mathrm{C}$, Zeocin, and $P$. pastoris strains $\mathrm{X}-33$ and KM71H were purchased from Invitrogen (Carlsbad, CA) as part of the P. pastoris EasySelect ${ }^{\mathrm{TM}}$ Expression Kit. pPICZ $\alpha \mathrm{C}$ and the rPTP gene were digested with the restriction enzymes XbaI and XhoI from New England Biolabs (NEB) for two hours at $37^{\circ} \mathrm{C}$. The newly digested vector and insert were purified using a QIAquick PCR Purification Kit. NEB's T4 ligase was used in the ligation of pPICZ $\alpha \mathrm{C}$ and $\mathrm{rPTP}$ at room temperature for two hours at $25^{\circ} \mathrm{C}$.

The resulting plasmid was transformed into XL1-Blue competent $E$. coli cells by first incubating the DNA on ice with the E. coli for 30 minutes. The cells were then heat pulsed for 30 seconds at $42^{\circ} \mathrm{C}$. The cells were incubated in SOC media at $37^{\circ} \mathrm{C}$ for one hour and then plated onto LB agar with Zeocin added. After approximately 12 hours of 
incubation at $37^{\circ} \mathrm{C}$, a sample was taken from each colony. The rPTP gene was PCR amplified from the plasmid and the resulting PCR products were Sangar sequenced. A clone with the correct sequence was selected and PCR was used to amplify and linearize the pPICZ $\alpha \mathrm{C}$ with rPTP insert. Because the $\mathrm{pPICZ} \alpha \mathrm{C}$ and insert were integrated into the P. pichia genome through homologous recombination, the plasmid must be linearized before transformation. The plasmid was purified using a Qiagen PCR cleanup kit so that Taq polymerase and primers were removed prior to transformation.

\section{Transformation of rPTP in P. pastoris:}

$50 \mu \mathrm{L}$ of competent X33 and KM71H cells were thawed on ice. $3 \mu \mathrm{g}$ of plasmid was added to each tube of competent cells. $1 \mathrm{~mL}$ of Solution II was added to each tube of cells and vortexed. The transformation reaction was incubated at $30^{\circ} \mathrm{C}$ for one hour and vortexed every 15 minutes. The cells were then heat shocked at $42^{\circ} \mathrm{C}$ for 10 minutes. The cells were then split into two $1.6 \mathrm{~mL}$ tubes and $1 \mathrm{~mL}$ of YPD was added to each tube. After incubation at $30^{\circ} \mathrm{C}$ for one hour, the cells were pelleted at 3,000 x g for 5 minutes. The supernatant was discarded and the pellet was resuspended in 500uL of Solution III, a salt solution provided by Invitrogen. The cells were pelleted at 3,000 x g for 5 minutes and resuspended in 100uL of Solution III. These cells were then plated on LB Agar with Zeocin. 


\section{Expression of rPTP in $P$. pastoris:}

Clones were selected from agar plates and restreaked onto new plates. Each clone was then used to inoculate $25 \mathrm{~mL}$ cultures of buffered complex medium containing glycerol (BMGY, $1 \%$ yeast extract, $2 \%$ peptone, $100 \mathrm{mM}$ potassium phosphate $\mathrm{pH}$ 6.0, $1.34 \% \mathrm{YNB}, 4 \times 10-5 \%$ biotin, $1 \%$ glycerol). The cultures were incubated at $25^{\circ} \mathrm{C}$ for 18 hours. The cells were pelleted at 2,000 x g for 10 minutes at $4^{\circ} \mathrm{C}$. Expression was then induced by resuspending the cells in buffered complex medium containing methanol (BMM, $100 \mathrm{mM}$ potassium phosphate $\mathrm{pH}$ 6.0, 1.34\% YNB, $4 \times 10-5 \%$ biotin, $1 \%, 0.5 \%$ methanol). After 48 hours of induction the cells were pelleted at 2,000 x g for 10 minutes. The supernatant was then removed and concentrated by centrifugal ultrafiltration using $15 \mathrm{~mL}$ Amicon filter units from Millipore with a molecular weight cut off of $10 \mathrm{kDa}$. A sample from each clone's ultrafiltrate was examined by SDS-PAGE and coomassie staining. One of the $\mathrm{KM} 71 \mathrm{H}$ clones was shown to have the highest yield and was used for all subsequent expressions.

To acquire sufficient rPTP for ${ }^{15} \mathrm{~N}$ NMR experiments, four liters of $P$. pastoris culture were grown. 500mL of BMGY media were inoculated the selected KM71H clone and incubated for 18 hours at $30^{\circ} \mathrm{C}$. The cells were then pelleted at 3,000 x g for 5 minutes. The cells were resuspended in BMM with $1.5 \mathrm{~g}{ }^{15} \mathrm{~N}$ ammonium sulfate per liter to a final OD600 of 0.6 in order to induce expression. The cells were cultured at $30^{\circ} \mathrm{C}$ for 4 days. The cells were pelleted at 3,000 x g for 5 minutes. The supernatant was concentrated into approximately $30 \mathrm{~mL}$ by centrifugal ultrafiltration using YM10 ultrafilters from Millipore. The concentrated was purified by size exclusion 
chromatography using Sephadex G-75 gel filtration medium resulting in a final ${ }^{15} \mathrm{~N}$ labeled rPTP yield of approximately $6 \mathrm{mg}$. 


\section{$\underline{\text { Results and Discussion: }}$}

\section{Functional characterization of PTP}

The primary sequence similarity between PTP and the other TIMPs suggests that PTP is likely the result of an ancient gene duplication. The similarity between the proteins presented a possible function for PTP as an inhibitor of metalloproteinases. In order to assess this, a group of human MMPs and a mouse MMP were selected. The MMPs were chosen to be representative of the categories of proteinases that MMPs fall into such as collagenases, gelatinases, and matrilysins. Using a wide range of MMPs from multiple species along with the broad range of inhibitory activity seen in TIMPs presented an opportunity for inhibitory activity of PTP, if present, to be demonstrated.

(Figure 7) PTP inhibition of MMP-1 was observed both initially and again over a range of PTP concentrations (Figure 8). Starting multiple trials of the MMP inhibition assay at once proved to be challenging and is likely responsible for some of the difficulties is assessing statistical significance of inhibition with some of the other MMPs. The effect of PTP binding to hMMP-2 presents an unexpected picture with regards to hypothesized TIMP-like activity. TIMPs have not been shown to activate any MMPs. However, TIMPs have been shown to bind to a wide range of MMPs and even pro-hMMP-2 to prevent its conversion to the active hMMP-2. The exact mechanism for MMP-2 activation is uncertain. However, it is an indication of PTP and MMP interaction, which still provides for PTP having a TIMP-like role. Other regulatory proteins have been shown to have inhibitory or activating role depending on the context so the kinetic data raises a dual regulatory role as a possibility of PTP function. ${ }^{[28]}$ 


\section{Localization and temporal expression within the mental gland}

In order to determine the localization and expression levels of PTP qualitatively, immunohistochemistry and confocal microscopy were employed. Immunohistochemistry involves the detection of antigens using antibodies. When used in the context of microscopy, antibodies can be labeled with a florescent reporter and used directly on tissue sections to reveal antigen localization.

Antibodies were used to label PTP, PRF, and collagen within the mental gland. $\alpha \mathrm{PTP}$ and $\alpha \mathrm{PRF}$ antibodies had been previously isolated as polyclonal antibodies from rabbit antisera whereas, acollagen is commercially available. In order to clearly visualize each antigen separately, the reporters with which each antibody is labeled were chosen form emission at different wavelengths. The presence of each antigen was then examined using a filter that only allows the wavelength of light to pass through that corresponds to a specific reporter. Confocal microscopy can be used in conjunction with fluorescentlylabeled tissue sections to generate images (Figure 6). Confocal microscopy provides advantages over conventional wide-field fluorescence microscopy in that optical resolution and contrast are improved in confocal microscopy.

\section{Characterization of the Expression and Localization of PTP}

The expression and localization of PTP within the mental gland was examined using confocal fluorescence microscopy. The micrographs generated can be seen in Figure 6. Examining the mental gland in June while it is early within its development reveals that in addition to a reduction in the lumen size of the mental gland, PTP is not expressed. As previously stated MMPs play a critical role in the tissue remodeling 
process. As the gland development is stimulated through an increase in testosterone levels, MMP activity is likely the mechanism through which the extracellular matrix is broken down to allow for the expansion of the mental gland. In order to maintain sufficient MMP activity for the mental gland to be expanded, PTP expression must be suppressed early in development. As the gland begins to mature, PTP expression is stimulated and its presence can be observed in the sample from August when the mental gland is mature.

PTP is present at a relatively high concentration in the $P$. shermani pheromone extract along with the other $P$. shermani pheromones such as PRF. In order to better understand how PTP is localized in the gland, PRF and PTP were observed on the same tissue section by confocal fluorescence microscopy. Merging the images taken of PRF and PTP in the mental gland tissue section reveals that PRF and PTP are colocalized within the mental glad. The co-secretion of PTP and PRF provides a biochemical signal that the mating season is ongoing. When the mental gland is stimulated PTP is released and coats the gland. By inhibiting MMP activity, PTP prevents regression of the mental gland from taking place thus preserving the gland.

\section{$\underline{\text { Expression of rPTP }}$}

Establishing that rPTP has the same structure as PTP is necessary when using rPTP in structural studies. Preliminary evidence suggests that the structures are identical. The reverse phase chromatography (Figure 9) indicates that they both have effectively the same retention times. Expression of rPTP permits future NMR studies to determine the

3D structure of this novel TIMP-like protein. By isotopically labeling $\mathrm{rPTP}$ with ${ }^{15} \mathrm{~N}$, 
multiple NMR experiments can be performed, such as ${ }^{15} \mathrm{~N}^{1} \mathrm{H}_{-}{ }^{15} \mathrm{~N}$ HSQC, NOESYHSQC, and ${ }^{15} \mathrm{~N}$-TOCSY-HSQC. Using this NMR data, nuclear Overhauser effects can be observed, which can then be used in conjunction with CS-Rosetta to predict an accurate model of the protein's 3D structure. ${ }^{[29]}$

Although ${ }^{13} \mathrm{C}$ carbon labeling would be useful for determination of an NMR solution structure of a protein of this size, the approach of combining the constraints from the disulfide bonding pattern with those from the NMR data is believed to be sufficient to yield a reasonable structural prediction. ${ }^{13} \mathrm{C}$ labeling was deemed prohibitively expensive due to the high cost of ${ }^{13} \mathrm{C}$-labeled methanol and the volume require during expression in P. pastoris. However, increasing the yield of rPTP in P. pastoris may be possible. The use of antifoaming agents in $P$. pastoris cultures has been shown to increase recombinant expression yield. ${ }^{[30]}$ The use of a P. pastoris clone with multiple copies of the rPTP gene may produce higher yield as well. Incremental induction using ${ }^{13} \mathrm{C}$ labeled methanol has also been shown to be an economical method for ${ }^{13} \mathrm{C}$ labeling. ${ }^{[31]}$ These techniques will be investigated provided that ${ }^{13} \mathrm{C}$ NMR experiments are necessary for greater resolution of the rPTP solution structure. 


\section{Conclusion}

Using an MMP inhibition assay to test the effectiveness of PTP as having TIMPlike activity revealed that PTP can inhibit MMP-1 by approximately $15 \%$. Using confocal fluorescence microscopy to observe the expression of PTP during the mating season indicated that when the gland is growing, PTP is not expressed. After the mental gland has matured, PTP expression levels are high. PTP is colocalized within the mental gland with PRF, which explains its presence in the pheromone extract. During courtship PTP is secreted coating the gland in PTP, which in turn inhibits MMPs from acting on the extracellular matrix. Regression of the gland is therefore prevented during the mating season. For future structural studies, a recombinant of PTP was expressed. rPTP has been shown to behave similarly in chromatography experiments. Future experiments, utilizing $\mathrm{CD}, \mathrm{MS}$ and disulfide bonding pattern analyses are expected to confirm that rPTP is structurally identical to PTP. 


\section{Table 1. Relative MMP Activity with Different PTP Concentrations}

\begin{tabular}{|l|l|l|l|l|l|l|}
\hline [PTP] (nM) & $\mathbf{0}$ & $\mathbf{0 . 0 2 2 5}$ & $\mathbf{0 . 2 2 5}$ & $\mathbf{2 . 2 5}$ & $\mathbf{2 2 . 5}$ & $\mathbf{2 2 5}$ \\
\hline $\mathbf{h M M P - 1}$ & 1.000 & 0.956 & 0.921 & 0.942 & 0.952 & $\mathbf{0 . 8 2 8 *}$ \\
\hline $\mathbf{h M M P - 2}$ & 1.000 & $1.172 *$ & $1.158^{*}$ & $1.258^{*}$ & $1.260^{*}$ & $1.313^{*}$ \\
\hline $\mathbf{h M M I P - 7}$ & 1.000 & 1.049 & 1.057 & 0.979 & 1.018 & 1.013 \\
\hline $\mathbf{h M M P - 8}$ & 1.000 & 0.956 & 0.959 & 0.935 & 0.930 & 0.905 \\
\hline mMMP-9 & 1.000 & 1.061 & 1.029 & 1.076 & 1.003 & $1.299^{*}$ \\
\hline hMMP-13 & 1.000 & 1.033 & 0.954 & 0.900 & 0.905 & 0.861 \\
\hline
\end{tabular}

Figure 7. MMP Inhibition Assay

Results from the MMP inhibition assay using varying concentrations of PTP. At a concentration of $225 \mathrm{nM}$, PTP shows statistically significant inhibition with a p-value of less than 0.05 . The assay also revealed statistically significant activation of hMMP-2 by PTP. It should be noted that the purpose of this experiment was to determine if PTP possessed any TIMP-like activity and was not meant to be a quantitative determination of hMMP and PTP binding. Therefore the $\mathrm{K}_{\mathrm{d}}$ and $\mathrm{K}_{\mathrm{i}}$ are not directly relevant to this study. 


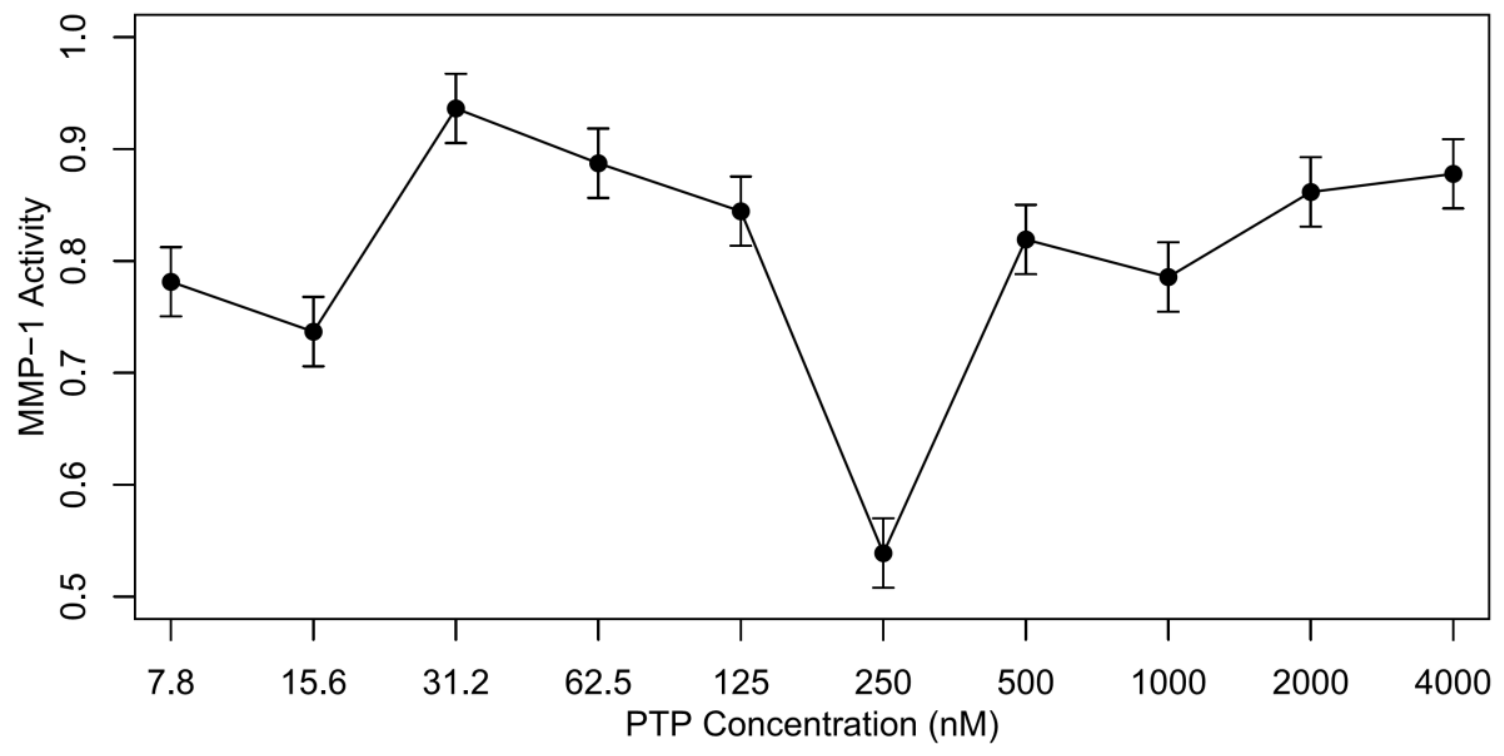

Figure 8.

MMP inhibition assay using MMP-1 with varying concentrations of PTP. All

concentrations of PTP evaluated from 7.8 to 4000 nM significantly inhibited MMP-1 by $15 \%$. The lack of a dose-dependent response prevents an exact quantification of MMP inhibition. Although the exact level of inhibition cannot be determined precisely, the inhibition of hMMP-1 by PTP in multiple trials provides evidence that PTP may have TIMP-like activity. 

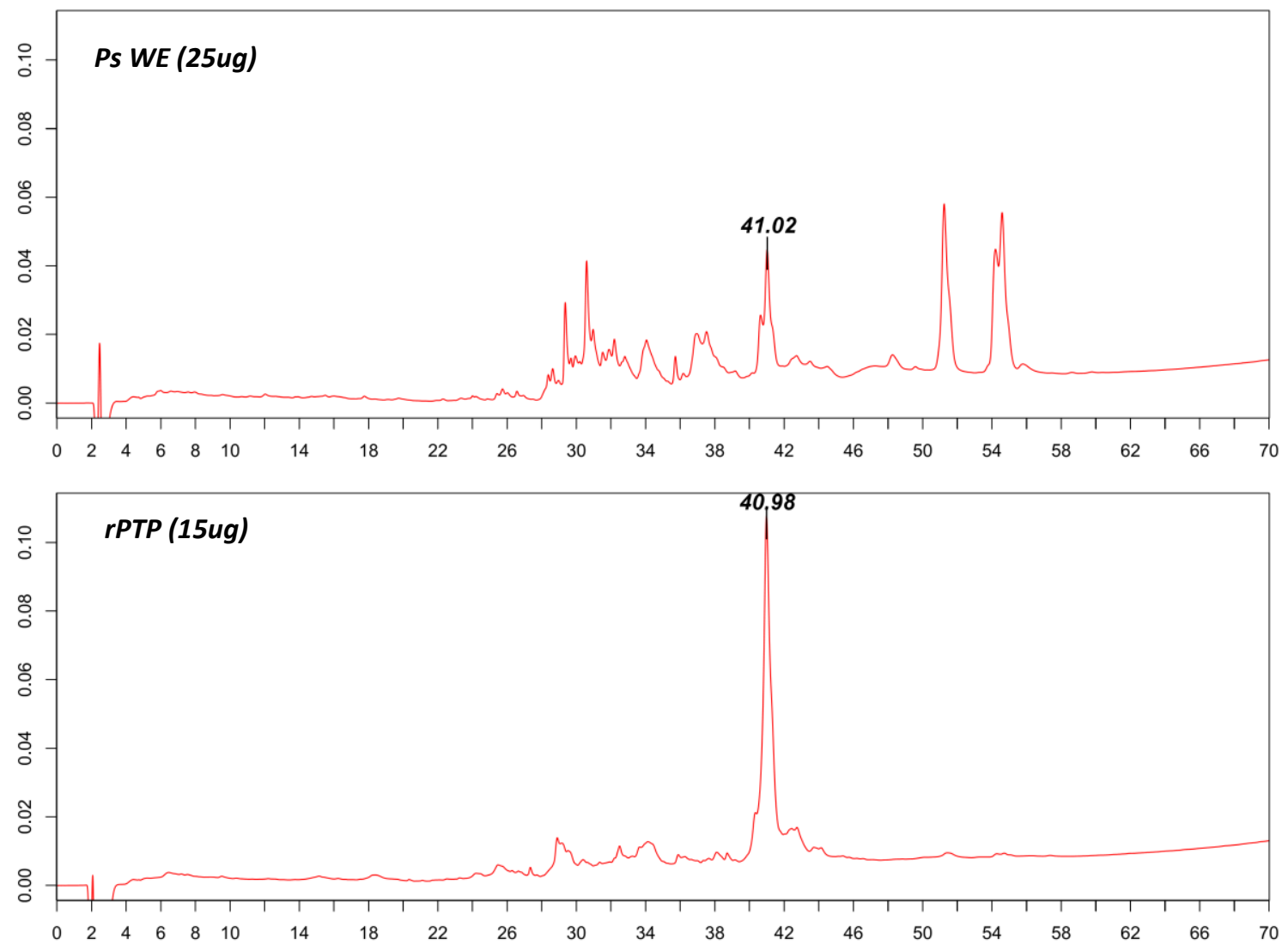

Figure 9. Reverse phase chromatograms of 25ug P. shermani whole extract (PsWE) and 15ug of rPTP. The retention times for PTP and rPTP only differ by 0.04 minutes, which is within the margin of error for reverse phase chromatography. 


\section{References}

1. Schubert, S.N., et al., The effects of sex on chemosensory communication in a terrestrial salamander (Plethodon shermani). Horm Behav, 2008. 54(2): p. 270-7.

2. Chouinard, A.J., et al., Individual variation in pheromone isoform ratios of the red-legged salamander, Plethodon shermani, in Chemical Signals in Vertebrates 12. 2013, Springer New York. p. 99-115.

3. Eddy, S., et al., -Sequential male mate choice in a terrestrial salamander, Plethodon shermani. Mutual Mate Choice in a Terrestrial Salamander, Plethodon shermani, with Long-Term Sperm Storage.: p. 56.

4. Wilburn, D.B., et al., Structural Insights into the Evolution of a Sexy Protein: Novel Topology and Restricted Backbone Flexibility in a Hypervariable Pheromone from the Red-Legged Salamander, Plethodon shermani. 2014.

5. Wilburn, D.B., et al., Pheromone isoform composition differentially affects female behaviour in the red-legged salamander, Plethodon shermani. Animal Behaviour, 2015. 100: p. 1-7.

6. Houck, L.D., et al., A recombinant courtship pheromone affects sexual receptivity in a plethodontid salamander. Chem Senses, 2008. 33(7): p. 623-31.

7. Schubert, S.N., et al., Effects of androgens on behavioral and vomeronasal responses to chemosensory cues in male terrestrial salamanders (Plethodon shermani). Hormones and Behavior, 2006. 50(3): p. 469-476.

8. Bejarano, P.A., et al., Degradation of basement membranes by human matrix metalloproteinase 3 (stromelysin). Biochem J, 1988. 256(2): p. 413-9.

9. Sternlicht, M.D. and Z. Werb, How matrix metalloproteinases regulate cell behavior. Annu Rev Cell Dev Biol, 2001. 17: p. 463-516.

10. Brew, K. and H. Nagase, The tissue inhibitors of metalloproteinases (TIMPs): An ancient family with structural and functional diversity. Biochimica et biophysica acta, 2010. 1803(1): p. 55-71.

11. Nagase, H., R. Visse, and G. Murphy, Structure and function of matrix metalloproteinases and TIMPs. Cardiovasc Res, 2006. 69(3): p. 562-73.

12. Gomis-Rth, F.-X., et al., Mechanism of inhibition of the human matrix metalloproteinase stromelysin-1 by TIMP-1. Nature, 1997. 389(6646): p. 77-81.

13. Seals, D.F. and S.A. Courtneidge, The ADAMs family of metalloproteases: multidomain proteins with multiple functions. Genes Dev, 2003. 17(1): p. 7-30.

14. Oka, O.B. and N.J. Bulleid, Forming disulfides in the endoplasmic reticulum. Biochim Biophys Acta, 2013. 1833(11): p. 2425-9.

15. Planson, A.G., et al., Assistance of maltose binding protein to the in vivo folding of the disulfide-rich $C$-terminal fragment from Plasmodium falciparum merozoite surface protein 1 expressed in Escherichia coli. Biochemistry, 2003. 42(45): p. 13202-11.

16. Vedvick, T., et al., High-level secretion of biologically active aprotinin from the yeast Pichia pastoris. J Ind Microbiol, 1991. 7(3): p. 197-201.

17. Pichia Expression Kit. Thermo Scientific.

18. Michel, W.C., et al., High-resolution functional labeling of vertebrate and invertebrate olfactory receptor neurons using agmatine, a channel-permeant cation. J Neurosci Methods, 1999. 90(2): p. 143-56. 
19. Woodley, S.K., Plasma Androgen Levels, Spermatogenesis, and Secondary Sexual Characteristics in Two Species of Plethodontid Salamanders with Dissociated Reproductive Patterns. General and Comparative Endocrinology, 1994. 96(2): p. 206-214.

20. Wilburn, D.B., et al., Proteomic and UTR analyses of a rapidly evolving hypervariable family of vertebrate pheromones. Evolution, 2012. 66(7): p. 222739.

21. Arafat, S.N., et al., Neutrophil Collagenase, Gelatinase, and Myeloperoxidase in Tears of Patients with Stevens-Johnson Syndrome and Ocular Cicatricial Pemphigoid. Ophthalmology, 2014. 121(1): p. 79-87.

22. Massova, I., et al., Matrix metalloproteinases: structures, evolution, and diversification. Faseb j, 1998. 12(12): p. 1075-95.

23. Visse, R. and H. Nagase, Matrix metalloproteinases and tissue inhibitors of metalloproteinases: structure, function, and biochemistry. Circ Res, 2003. 92(8): p. 827-39.

24. Rawlings, N.D., et al., MEROPS: the database of proteolytic enzymes, their substrates and inhibitors. Nucleic Acids Research, 2014. 42(D1): p. D503-D509.

25. Kapust, R.B. and D.S. Waugh, Escherichia coli maltose-binding protein is uncommonly effective at promoting the solubility of polypeptides to which it is fused. Protein Science : A Publication of the Protein Society, 1999. 8(8): p. 16681674.

26. Ahmad, M., et al., Protein expression in Pichia pastoris: recent achievements and perspectives for heterologous protein production. Applied Microbiology and Biotechnology, 2014. 98(12): p. 5301-5317.

27. Delic, M., et al., The secretory pathway: exploring yeast diversity. FEMS Microbiol Rev, 2013. 37(6): p. 872-914.

28. Mikels, A.J. and R. Nusse, Purified Wnt5a Protein Activates or Inhibits ?Catenin?TCF Signaling Depending on Receptor Context. PLoS Biol, 2006. 4(4): p. e115.

29. Shen, Y., et al., De novo protein structure generation from incomplete chemical shift assignments. Journal of biomolecular NMR, 2009. 43(2): p. 63-78.

30. Routledge, S.J., et al., Antifoam addition to shake flask cultures of recombinant Pichia pastoris increases yield. Microbial Cell Factories, 2011. 10: p. 17-17.

31. Rodriguez, E. and N.R. Krishna, An economical method for (15)N/(13)C isotopic labeling of proteins expressed in Pichia pastoris. J Biochem, 2001. 130(1): p. 1922. 